\title{
Malaria parasitaemia and socioeconomic status of selected residents of Emohua community, Rivers State, Nigeria
}

\author{
*Abah, A.E.,Awi-Waadu,G.D.B.,Nduka, F. O. and Richard, A. \\ Department of Animal and Environmental Biology, University of Port Harcourt PMB5323 Port Harcourt \\ 50001, Rivers State, Nigeria.
}

\begin{abstract}
In Nigeria, malaria consistently ranks among the five most common cause of death in children. This study investigated the prevalence of malaria and socioeconomic status of someresidents of Emohua Community, Rivers State, Nigeria.Following ethical clearance which was obtained from the University of Port Harcourt and the parents of the subjects who gave their written consents, blood samples were collected through vein puncture from 200 subjects within the age 0-17years, from July 2014-February 2015. Structured questionnaire were administered to the subjects and parents provided answers for younger children.Thick and Thin films were examined microscopically using oil immersion objective following the standardparasitological method. The thin films were fixed with methanol and all films were stained with $10 \%$ Giemsa stain diluted with 7.2 buffer water for 10 minutes. The demographic characteristics of 200 subjects examined in Emohua showed that 120(60\%) were females and $60(40 \%)$ were males. Sex related prevalence showed that more females were infected with 66(62.3\%) and had higher parasite density of 144720/ul than males with $40(37.7 \%)$ and parasite density of $106160 /$ ul though the difference was not significant $(P>0.05)$. Out of the 200 subjects examined, 106(53.0\%) were positive for Plasmodium falciparum. Age related prevalence showed that subjects within the age 0-3years and 4-6years had higher prevalence of $62(31 \%)$ followed by those within the age 7-9years with 31(15.5\%) and the least with zero prevalence was within the age 16-18 years. Those within the age of 4-6years had higher parasite density of 71680/ul followed by 0-3years of age with parasite density of 63360/ul while those within the age 16-18yrs had none (0). The difference in prevalence of malaria in relation to age was significant $(P<0.05)$. In relation to socio-economic status, Subjects within the lower class had greater percentage of 131 (65.5\%), followed by high class with 45(22.5\%) and the least was middle class with 24(12\%). Subjects in lower class were more infected with the highest prevalence of 75(57.3\%) and highest parasite density of 182800/ul followed by subjects in higher class with 21(46.7\%) and parasite density of 48960/ul and the least prevalence of 10(41.7 $\%)$ with parasite density of 19120/ul was recorded in the middle class. The prevalence of malaria between the socio-economic class was not significant $(P>0.05)$. Subjects that used treated net were more with $117(58.5 \%)$, followed by those that do not use net at all with 54(27\%) and those whose nets were untreated with $28(14 \%)$. Only $1(0.5 \%)$ person believed in the potency of prayer as a preventive measure against malaria while none trusted environmental sanitation. Subjects that are non- net users had higher prevalence of 46(85.2\%) and more parasite density of 98080/ul followed by the untreated net users with 22(78.6\%) and parasite density of 77280/ul while the least prevalence was recorded among the treated net users with 38(32.5\%) and parasite density of 75520/ul. The differences in prevalence of infection in relation to preventive measures was significant $(P<0.05)$.More persons patronized patent drug seller 60(38.5\%) followed by Hospital 52(33.3\%) and clinic $44(28.3 \%)$ also more persons had non-formal education 92(59.0\%) followed by those with formal education 61(39.1\%) and those with none at all 3(1.9). Subjects that had formal education sought more treatment in the hospital 40(65.6\%) than those with non -formal education 12(13.0\%) while those with non-formal education sought treatment more with the patent drug seller 52(56.5\%) followed by clinic 28(30.4\%) compared to subjects with formal education 5(8.2\%) and 16(26.2\%) for patent drug seller and clinic respectively. Those with no form of education 3(100\%) sought treatment with patent drug sellers. The differences in treatment seeking behaviour in relation to education was significant $(P<0.05)$. There is need to improve socio-economic status and awareness for total compliance to preventive measures among the subjects so as to reduce the malaria prevalence rate to the desired zero level.
\end{abstract}

Keywords: Malaria parasitaemia, Socio-economic status, Emohua community, Rivers State, Nigeria.

\section{Introduction}

An estimated 3.3billion people are at risk of being infected with malaria and developing disease, and 1.2 billion are at high risk(WHO,2014).Malaria is the $2^{\text {nd }}$ leading cause of death from infectious diseases in Africa, after HIV/AIDS (NMFS,2011). Malaria exacts a heavy burden on most vulnerable communities where the poorest are most severely affected, having the highest risks associated with malaria, and the least access to effective services for prevention, diagnosis and treatment (WHO,2014).Malaria is caused by five species of the parasite belonging to the genus Plasmodium. Out of which four, namely: P. falciparum, P.vivax.P.malariaeand 
P.ovale affect humans whileP.knowlesi that causes malaria among monkeys, has been incriminated in recent years in human malaria cases(WHO,2015).

Malaria has been estimated to cost Africa more than US\$ 12 billion every year lost GDP. Malaria stricken family spends an average of over one quarter of her income on malaria treatment and can only harvest $40 \%$ of crops harvested by healthy families (Fact Sheet, 2004). It is estimated that US $\$ 5.1$ billion is required to achieve global targets for malaria control and elimination (WHO, 2014). In Nigeria, it is estimated that about 132billion Naira is lost to malaria annually in the form of treatment costs, prevention and loss of man hour(FMOH,2009 and NMCP, 2012).Yet malaria remains a major public health challenge where it accounts for more cases and death than any other country in the world (CDC,2012). High prevalence of malaria parasitaemia has been reported in Nigeria (Kaluet al., 2012; Olasehindeet al., 2010 and Abah and Temple, 2015). In SouthSouth zone of Nigeria where Rivers State is situated, malaria has an average prevalence of $32.2 \%$ among children within the age of 6-59 months (NMFS, 2011). The variation among other target groups is not much, as prevalence of $28.0 \%$ was recorded among blood donors in Port Harcourt (Abah and Joe-Cliff, 2016) and 26.0\% prevalence was reported among pregnant women attending ante-natal clinic in Port Harcourt ( Abah and Moses,2015; Woguet al.,2013).

Malaria can be prevented and treated by highly cost-effective interventions such as vector control, chemoprevention and case management(WHO,2014) and according to report by WHO (2014) the coverage of these steps have increased substantially in the last 10years. Hence, the current level of awareness, compliance with the procedures and the socio-economic status of the people needs to be established. The aim of the present study is to determine the prevalence of malaria and socio-economic status of residents ofEmohua community in Rivers State, Nigeria.

\section{Materials and Methods}

Ethical clearance: Ethical clearance was obtained from the University of Port Harcourt and the parents of the subjects gave their written consents.

Study Area: Emohua is the local government headquarter of EmohuaLocal Government Area (LGA) of Rivers State, Nigeria. It has an area of $831 \mathrm{~km}^{2}(321 \mathrm{sq} \mathrm{mi})$ and a population of 201,901 as at the 2006 census. Its coordinates are $4^{\circ} 53^{\prime} 0^{\prime \prime} \mathrm{N}$ and $6^{\circ} 52^{\prime} 0^{\prime}$ ' $\mathrm{E}$. The annual relative humidity is over $80 \%$, mean annual temperature range of $23-32^{\circ} \mathrm{C}$ and heavy rainfall of $2000 \mathrm{~mm}-2500 \mathrm{~mm}$ per annum. Emohua sampling point which is the general Hospital is located at $6^{\circ} 51^{\prime} 55^{\prime \prime} \mathrm{E}$ and $4^{\circ} 52^{\prime} 26^{\prime \prime} \mathrm{N}$. The major occupations of the residents are farming and small scale business. Three types of forest are found in Emohua; mangrove forest, fresh water swamp forest and low land rain forest.

Sample Collection: Blood samples were collected through the vein puncture from 200 subjects within the ages of 0-17yearsbetween July 2014-February 2015.Structured questionnaires were administered and parents provided answers for younger children. Two millilitres of blood was collected and gently dispensed into Ethylene Diamine Tetra-Acetic acid (EDTA) bottle and thoroughly mixed. Collected samples were transported to the laboratory.

Sample Preparation: Thick and Thin films were prepared, air dried, stained and examined microscopically using oil immersion objective. The thin films were fixed with methanol and all films were stained with $10 \%$ Giemsa stain diluted with 7.2 buffer water for 10 minutes following standard procedure described by Cheesbrough (2005).

The number of parasites per $u$ of blood was calculated using the relative value method (WHO standard) as

$\frac{\text { parasite count } x 8000}{\text { set range of WBC }}=$

\section{Statistical analysis}

The data collected were analysed using descriptive statistics (Tables and Charts) and Chi square $\left(\mathrm{X}^{2}\right)$ analysis at $5 \%$ significant level. SPSS package was used.

\section{Results}

The demographic characteristics of 200 subjects examined in Emohua (Table 1) showed that 120(60\%) were females and 60(40\%) were males. Sex related prevalence in Emohua community showed that more females were infected with 66(62.3\%) and had higher parasite density of 144720/ul than males with $40(37.7 \%)$ and parasite density of 106160/ul (Table 2) though the difference was not significant $(\mathrm{P}>0.05)$. Out of the 200 subjects examined, 106(53.0\%) were positive for Plasmodium falciparum (Table3). 
Table1.Demograhic characteristics of the study populations in EmohuaCommunity,Rivers State, Nigeria.

\begin{tabular}{|l|l|}
\hline Characteristics & Emohua, N=200 \\
\hline Sex & \\
\hline Female & $120(60)$ \\
\hline Male & $80(40)$ \\
\hline Age group in years & $62(31)$ \\
\hline $0-3 y r s$ & $62(31)$ \\
\hline 4-6yrs & $31(15.5)$ \\
\hline $7-9 y r s$ & $23(11.5)$ \\
\hline $10-12$ yrs & $22(11)$ \\
\hline $13-15 y r s$ & $0(0)$ \\
\hline $16-18 y r s$ & \\
\hline Socio Economic status & $45(22.5)$ \\
\hline Higher class & $24(12)$ \\
\hline Middle class & $131(65.5)$ \\
\hline Lower class &
\end{tabular}

Percentage in parenthesis

Table 2.Sex related prevalence of malaria parasitaemia in Emohua community, Rivers State, Nigeria.

\begin{tabular}{|c|c|c|c|c|c|}
\hline Study Areas & No. Examined & No. Positive (\%) & Parasite Density $(u l)$ & $\mathrm{X}^{2}$ & P-Value \\
\hline & $\mathrm{M}$ & $\mathrm{M}$ & $\mathrm{M}$ & & \\
\hline Emohua & 120 & $66(55.0)$ & 144720 & 0.48 & 0.488 \\
\hline
\end{tabular}

Table 3.Malaria parasitaemia and plasmodium species in Emohua community, Rivers State, Nigeria.

\begin{tabular}{|l|l|l|l|l|}
\hline & & & \\
\hline Prevalence & No.Examined & No.Positive\% & Plasmodium species & \\
\hline Emohua & 200 & $106(53)$ & Plasmodium falciparum & \\
\hline
\end{tabular}

Age related prevalence showed that subjects within the age 0-3years and 4-6years had higher prevalence of $62(31 \%)$ followed by those within the age 7-9years with $31(15.5 \%)$ and the least with zero prevalence was within the age 16-18 years. Those within the age of 4-6years had higher parasite density of $71680 / u l$ followed by $0-3$ years of age with parasite density of 63360/ul while those within the age 16-18yrs had none $(0)$ (Table 4). The difference in prevalence of malaria in relation to age was significant $(\mathrm{P}<0.05)$.

In relation to socio-economic status, Subjects within the lower class had greater percentage of 131 $(65.5 \%)$, followed by high class with $45(22.5 \%)$ and the least was middle class with $24(12 \%)$. Subjects in lower class were more infected with the highest prevalence of $75(57.3 \%)$ and highest parasite density of $182800 / u l$ followed by subjects in higher class with $21(46.7 \%)$ and parasite density of 48960/ul and the least prevalence of $10(41.7 \%)$ with parasite density of 19120/ul was recorded in the middle class (Table 5). The prevalence of malaria between the socio-economic class was not significant $(\mathrm{P}>0.05)$.

Subjects that used treated net were more with $117(58.5 \%)$, followed by those that do not use net at all with $54(27 \%)$ and those whose nets were untreated with $28(14 \%)$. Only $1(0.5 \%)$ person believed in the potency of prayer as a preventive measure against malaria while none trusted environmental sanitation. Subjects that are non- net users had higher prevalence of 46(85.2\%) and more parasite density of 98080/ul followed by the untreated net users with $22(78.6 \%)$ and parasite density of $77280 / u l$ while the least prevalence was recorded among the treated net users with 38(32.5\%) and parasite density of 75520/ul (table 7). The differences in prevalence of infection in relation to preventive measures was significant $(\mathrm{P}<0.05)$.

More persons patronized patent drug seller 60(38.5\%) followed by Hospital $52(33.3 \%)$ and clinic 44(28.3\%) also more persons had non-formal education 92(59.0\%) followed by those with formal education61(39.1\%) and those with none at all 3(1.9)(Table 3). Subjects that had formal education sought more treatment in the hospital $40(65.6 \%)$ than those with non -formal education12(13.0\%) while those with nonformal education sought treatment more with the patent drug seller 52(56.5\%) followed by clinic $28(30.4 \%)$ compared to subjects with formal education 5(8.2\%) and $16(26.2 \%)$ for patent drug seller and clinic respectively (table 8). Those with no form of education 3(100\%) sought treatment with patent drug sellers. The differences in treatment seeking behaviour in relation to education was significant $(\mathrm{P}<0.05)$. 
Table 4.Prevalence of malaria Parasitaemia by age in Emohua Community, Rivers State, Nigeria.

\begin{tabular}{|c|c|c|c|c|c|}
\hline & Emohua & & & & \\
\hline Age group(yrs) & No.Examined & No.positve (\%) & Parasite density & $\mathbf{X}^{2}$ & P-value \\
\hline $0-3 \mathrm{yr}$ & 62 & $26(41.9)$ & 63360 & & \\
\hline $4-6 y r$ & 62 & $38(61.3)$ & 71680 & & \\
\hline $7-9 \mathrm{yr}$ & 31 & $15(48.4)$ & 45440 & & 0.016 \\
\hline $10-12 \mathrm{yr}$ & 23 & $18(78.3)$ & 43680 & 12.205 & 0.016 \\
\hline $13-15 y r$ & 22 & $9(40.9)$ & 26720 & & \\
\hline $16-18 \mathrm{yr}$ & 0 & 0 & 0 & & \\
\hline Total & 200 & $106(53)$ & 250880 & & \\
\hline
\end{tabular}

\section{$\mathrm{X}^{2}=$ chi-square}

Table5:Prevalence of malaria parasitaemia according to socio-Economic Status in Emohua Community, Rivers State, Nigeria.

\begin{tabular}{|l|l|l|l|l|l|}
\hline & Emohua & & & & \\
\hline S.E Class & No. Examined & No.positive(\%) & Parasite Density(ul) & $\mathbf{X}^{\mathbf{2}}$ & P-value \\
\hline Higher class & 45 & $21(46.7)$ & 48960 & & \\
\hline Middle Class & 24 & $10(41.7)$ & 19120 & 2.91 & 0.233 \\
\hline Lower Class & 131 & $75(57.3)$ & 182800 & & \\
\hline Total & $\mathbf{2 0 0}$ & $\mathbf{1 0 6}(\mathbf{5 3})$ & $\mathbf{2 5 0 8 8 0}$ & & \\
\hline
\end{tabular}

$\mathrm{No}=$ Number, $\mathrm{S} . \mathrm{E}=$ Socioeconomic,$+\mathrm{ve}=$ Positive, $\mathrm{P} . \mathrm{D}=$ Parasite Density, $\mathrm{X}^{2}=$ Chi-Square

Table7:Prevalence of malaria parasitaemia in relation to preventive measuresin Emohua Community, Rivers State, Nigeria.

\begin{tabular}{|c|c|c|c|c|c|}
\hline & Emohua & & & & \\
\hline Prevention & $\begin{array}{l}\text { No. } \\
\text { Examined }\end{array}$ & No. positive(\%) & Parasite density(ul) & $\mathrm{X}^{2}$ & P-Value \\
\hline \multicolumn{6}{|l|}{ Net } \\
\hline Treated net users & 117 & $38(32.5)$ & 77280 & & \\
\hline untreated net users & 28 & $22(78.6)$ & 75520 & 50.71 & 0.000 \\
\hline non net users & 54 & $46(85.2)$ & 98080 & & \\
\hline Others & & & & & \\
\hline \multicolumn{2}{|c|}{ Env'mental sanitation } & 0 & 0 & & \\
\hline Prayer & 1 & 0 & 0 & & \\
\hline Total & 200 & $106(53)$ & 250880 & & \\
\hline
\end{tabular}

$\mathbf{X}^{2}=$ Chi-square

\begin{tabular}{|l|l|l|l|l|l|l|l|l|l|}
\hline \multicolumn{7}{|c|}{ Table 8.Treatment seeking behaviour in relation to Education among respondents in Emohua } & & & \\
\hline & Community, Rivers State, Nigeria. & & & & \\
\hline Study Area. & Education & Hospital & Clinic & Dispensary & SM & PDS & Total & $\mathbf{X}^{\mathbf{2}}$ & P-Value \\
\hline Emohua & Formal & $40(65.6)$ & $16(26.2)$ & 0 & 0 & $5(8.2)$ & 61 & & \\
\hline & Informal & $12(13.0)$ & $28(30.4)$ & 0 & 0 & $52(56.5)$ & 92 & 97 & 0.000 \\
\hline & None & 0 & 0 & 0 & 0 & $3(100)$ & 3 & & \\
\hline & Total & $\mathbf{5 2 ( 3 3 . 3 )}$ & $\mathbf{4 4}(\mathbf{2 8 . 2})$ & $\mathbf{0}$ & $\mathbf{0}$ & $\mathbf{6 0}(\mathbf{3 8 . 5})$ & $\mathbf{1 5 6}$ & & \\
\hline
\end{tabular}

$\mathrm{PDS}=$ patent drug sellers, $\mathrm{SM}=$ Self-medication, $\mathrm{X}^{2}=$ Chi-Square.

\section{Discussion}

The overall prevalence of $53.0 \%$ was recorded in the present study. This prevalence is high when compared with the global decline in malaria incidence which fell by $37 \%$ between 2000 and 2015 but buttresses the fact that Africa carries a disproportionately high share of the global malaria burden(WHO,2015). High prevalence has been reported in Nigeria by many researchers but the present prevalence is lower than what was reported by Kaluet al., (2012) in Aba and Umuahia urban areas of Abia State,Olasehindeet al.,(2010) in Ota, Ogun State, South western Nigeria and AbahandTemple,(2015) in Angiama Community, Bayelsa State, Nigeria. However, it is higher than the average prevalence reported in the South-South zone by NMFS (2011). This may be due to the fact thatEmohua is a rural setting and rural environments encourage breeding of malaria vector by the presence of swamps, marshes, stagnant pools, tree holes, septic ditches etc.

Plasmodium species identified in the present study was the Plasmodium falciparum. This corroborates earlier observations made by previous researchers in the south-south zone ofNigeria (Pondeiet al.,2012; Woguet al.,2013;Abahand Temple,2015).Moreso, WHO had earlier established that Plasmodium falciparum remains the most common Plasmoduimspecies across much of Sub-Saharan Africa.

More persons patronized Patent drug seller (38.5\%) than hospitals (33.3\%) and clinics $(28.3 \%)$. This is not surprising because it has been established that Medicine sellers are generally closer to homes than formal facilities (Adomeet al.,1996; Van der Geest, 1987; Ene-Obonget al.,2000). Moreover, their service is faster and 
they maintain a weekly opening hours which may be twice as long as those in some health facilities (Goodman,2004) and like many other business, their existence is maintained in response to consumer demand, in this case for accessible, convenient, reliable and affordable antimalarial drugs. The higher patronage of the patent drug seller may also have to do with the level of Education and socio -economic status of the subjects as ignorance and poverty play a major role in incidence and prevalence of parasitic diseases.

The prevalence in relation to Sex shows that more females $62.3 \%$ were infected than males $37.7 \%$. Also the parasite density was higher in females 144720/ul than in males106160/ul. The present finding is in contrast to earlier observation by Houmsouet al.,(2011) and Abah and Temple (2015) thatobserved higherprevalence of malaria in males than females. The present finding may be due to the fact that females are nurtured to assist their mothers in sweeping compounds and food preparation at dawn and dusk, involving fetching water from dug wells and washing dishes outside and so has greater exposure to mosquito bites since mosquitoes are known to bite more at such times( Mosquito world, 2016)

Those within the age 4-6yrs had higher parasite density of 71680/ul followed by 0-3years 63360/ul . Similar observations was made earlier by Abah and Temple (2015). This finding is in line with WHOposition that $90 \%$ of all death due to malaria occur in Sub-Saharan Africa and children under 5 years account for $78 \%$ of all deaths (WHO,2014) and also children of older age tend to develop immunity due to progressive acquisition of immunity as a result of subsequent exposure to malaria parasite (Blolandet al.,1999).

In relation to socio-economic status, Subjects in lower class had higher prevalence $75(57.3 \%)$ and had higher parasite density of $182800 / u l$. This finding is expected because Emohua is a rural community and Malaria is frequently referred to as the disease of the poor (Worallet al.,2003) and also WHO (2014) inferred that Malaria exacted a heavy burden on the poorest and the most vulnerable communities where the poorest are most severely affected as a result of their inability to procure drugs or secure treatments.

Prevalence of infection in relation to preventive measures show that subjects that are non- net users had higher prevalence 46(85.2\%) and more parasite density 98080/ul compared to other groups. This observation supports the need to use insecticide treated nets (ITNs) which have been shown to reduce severe disease and mortality due to malaria (CDC,2004). Also the use of insecticide treated net to prevent mosquito bites has become a very important malaria control strategy in the absence of effective vaccine for malaria prevention and development of unacceptable level of resistance to drugs by the malaria parasites (TerKuile et al.,2003; Lengeler and Snow, 2000)

\section{Conclusion}

Malaria prevalence in Emohua community remains high despite the global decline in malaria incidence. Majority of the residents of the community falls within the lower class of the socio-economic status. Concerted efforts needs to be made to improve the socio-economic status of the residents and to reduce the prevalence of malaria in the community to the desired zero level byrelevant bodies and government.

\section{Reference}

[1]. Abah, A.E. and Joe-Cliff, O (2016), Current status of malaria parasite among blood donorsin Port Harcourt, Rivers State, Nigeria Journal of Applied Science and Environmental Management 20(1):187-191

[2]. Abah, A.E. and Temple, B (2015), Prevalence of Malaria Parasite among Asymptomatic Primary School Children in Angiama Community,Bayelsa State, Nigeria. Tropical Medicine and Surgery 4(1):203-207

[3]. Abah, A. E. and Moses, L (2015), Plasmodiumparasitaemia among pregnant women attending Ante-Natal Clinic at Military Hospital Port Harcourt, Rivers State,Nigeria.ScientiaAfricana.14 (2):157-162

[4]. Adome, R.O.Whyte,S.R andHardon, A (1996), Popular pills: Community drug use in Uganda. Het Spinhuis, Amsterdam.

[5]. Bloland, P.B.Boriga, D.A.Ruebush, T.K.McCormick,J.B.Roberts,J.M.Oloo,A.J.Hawley, W. Lai. A,

[6]. Nahlen,Band Campbell, C.C(1999), Longitudinal cohort study of epidemiology of malaria infection in an area of intense Malaria transmission II. Descriptive epidemiology of malariainfection and disease among children. American Journal of Tropical Medicine and Hygiene60: 641-648.

[7]. CDC (Centre for Disease Control) (2012) Atlanta co 800-CDC-info. US Department and Health.

[8]. CDC (Centre for Disease Control)(2004), Malaria during pregnancy. Department of Health andHuman Services, US Centre for Disease Control and Prevention. Atlanta.

[9]. Cheesbrough, M. (2005), District Laboratory Manual for tropical countries. 2Nd Edition updateVol. 1. Bulterworth -heinemann Ltd. Oxford ox28DP.pp. 249.

[10]. Ene-Obong,H.N.,Iroegbu, C.U andUwaegbute, A.C (2000). Perceived causes and management of diarrhoea in young children by market women in Enugu state Nigeria.Journal of Health populNutr 18;92-102 (pubmed 11057065

[11]. Fact Sheet(2004), Malaria, A global Crisis. UNICEF and UN WWW.unicef.orgAssessed 22 May2016.

[12]. Federal Ministry Of Health (FMOH, 2009),Federal Republic of Nigeria training manual formanagement of malaria in Nigeria, participant manual malaria and vector controldivision Abuja, Nigeria, Last accessed Dec,2014.

[13]. Goodman, C.A. (2004), An economic analysisof the retail market for fever and malariatreatmentin Rural Tanzania: PhD Thesis, Department of public Health and Policy,London School of hygiene and tropical medicine, University of London.

[14]. Houmsou R.S., Amuta E.U., Sar T.T and Adagba A.H (2011), Malarial infection among patients attending a Nigerian semi-urban based hospital and performance of HRP-2 pf rapid diagnostic test (RDT) in screening clinical cases of Plasmodium falciparum malaria. iMedpub journal 2:1.5 doi:10:3823/422

[15]. Kalu Mong Kalu, NwogoAjukaObasi, Florence OnyemachiNduka, Glory Otuchristian (2012) Acomparative study of the prevalence of Malaria in Aba and Umuahia urban areas of AbiaState, Nigeria. Research Journal of Parasitology 7: 17-24. 
[16]. Lengeler C and Snow R.W (2000), From efficacy to effectiveness: insecticides treated bed nets in Africa. Bulletin World Health Organization 74:325-332

[17]. Mosquito World (2016). Your guide to effective mosquito control. WWW.mosquitoworld.net/Mosquito feeding habits. assessed 23 may 2016.

[18]. NMFS (Nigeria Malaria Fact Sheet) (2011). United States Embassy in Nigeria.

[19]. National Malaria Control Programme (NMCP, 2012), Four out of ten children have malaria; New survey in malaria prevalence among Nigeria Children 2010

[20]. Olasehinde, G.I., A.A.Ajayi, S.O.Taiwo, B.T.Adekeye and O.A Adeyeba (2010), Prevalence and Management of Faciparium Malaria among infants and children in Ota, Ogun State, South western Nigeria. African Journal of Clinical and Experimental Microbiology 11: 159-163.

[21]. Pondeikemebradikumo, EbidorLawani, EnoNdiok (2012), Prevalence of the malaria parasitein screened blood in a tertiary health centre in the malaria-endemic Niger Delta region ofNigeria. Global Advance Research Journal of Microbiology, 1(11):188-193.

[22]. TerKuile F.O, Terlouw D.J, Phillips-Howard P.A, Hawley W.A, Friedman J.F, Kariuki S.K, Shi Y.P,Kolczak M.S, Lai A.A, Vulule J.M Nahlen B.L (2003), Reduction of Malarai during pregnancyby permethrin-treated bed nets in an area of intense perennial malaria transmission in western Kenya.American Journal of Tropical Medicine and Hygiene 68(4):50-60

[23]. Van der Geest, S (1987) Self-care and the informal sale of drugs in south Cameroun. Social Science and Medicine 25293-305 (PubMed:3629303

[24]. WHO (2014). World malaria report 2014. World Health Organization, 20 Avenue Appia, 1211 Geneva 27, Switzerland

[25]. WHO, (2015), World Health Organization, Malaria Fact Sheet No.94. WHO Geneva.

[26]. WOGU Michael N, Florence O. NDUKA and MacDonald D. WOGU (2013), Prevalence ofMalaria Parasite Infection among Pregnant Women Attending Antenatal Clinics inPort Harcourt, Rivers State, Nigeria.

[27]. International Journal of TROPICAL DISEASE \& Health 3(2): 126-132,

[28]. Worrall E., Basu S. and Hanson K (2003), the relationship between socio-economic status andmalaria: A review of literature. Background papers for ensuring that malaria control intervention reach the poor. London School of Tropical Medicine Pp 1-56 